\title{
Degree Unit of Plane Angle
}

National Cancer Institute

\section{Source}

National Cancer Institute. Degree Unit of Plane Angle. NCI Thesaurus. Code C68667.

A unit of plane angle measurement equal to the length of the arc cut out by the angle, divided by the circumference of the circle, and multiplied by 360 . The symbol for degrees is a small superscript circle. One radian is about 57 degrees and one degree is pi/180 radians. 